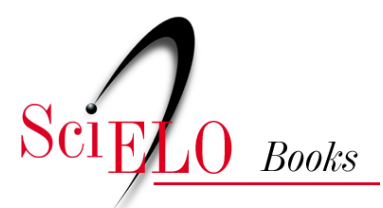

\title{
33. Como um Tratador de Cães Contribuiu para o Progresso da Radiologia
}

\author{
Joffre Marcondes de Rezende
}

\section{SciELO Books / SciELO Livros / SciELO Libros}

REZENDE, J. M. Como um Tratador de Cães Contribuiu para o Progresso da Radiologia. In: À sombra do plátano: crônicas de história da medicina [online]. São Paulo: Editora Unifesp, 2009, pp. 269-272. História da Medicina series, vol. 2. ISBN 978-85-61673-63-5. https://doi.org/10.7476/9788561673635.0034.

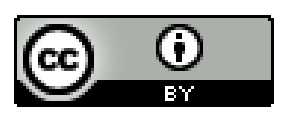

All the contents of this work, except where otherwise noted, is licensed under a Creative Commons Attribution 4.0 International license.

Todo o conteúdo deste trabalho, exceto quando houver ressalva, é publicado sob a licença Creative Commons Atribição 4.0.

Todo el contenido de esta obra, excepto donde se indique lo contrario, está bajo licencia de la licencia Creative Commons Reconocimento 4.0. 


\section{Como um Tratador de Cães Contribuiu para o Progresso da Radiologia}

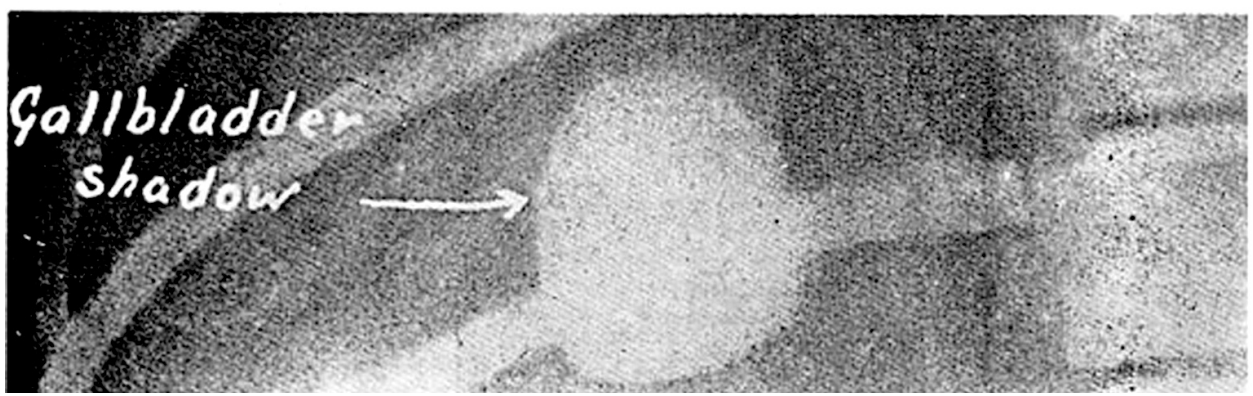

Colecistografia obtida pela primeira vez em um cão em 1923.

A história da colecistografia é um exemplo bem ilustrativo de que a mente 1 humana, por mais brilhante e preparada que seja, deixa de perceber noções aparentemente óbvias, assim consideradas a posteriori. E também de como ocorrências imprevistas podem contribuir para clarear o caminho da pesquisa científica.

No início do século xx, a radiologia era o único método de diagnóstico por imagem de que dispunha a medicina. A cada dia os equipamentos eram aprimorados e novas técnicas de exame eram descritas ou aperfeiçoadas.

O exame contrastado do tubo digestivo, inicialmente com sais de bismuto e, a seguir, com sulfato de bário, já estava sendo empregado com sucesso no diagnóstico das doenças do estômago e do cólon.

A vesícula biliar, entretanto, permanecia inacessível aos raios-X para estudo da sua patologia. O máximo que se podia conseguir era a imagem de cálculos radiopacos em radiografias simples do abdome. A primeira referência à imagem de cálculos biliares em um paciente data de ı 898, porém, somente em I9I I, graças ao avanço da tecnologia e à maior experiência dos 
radiologistas, foi possível detectar a bile cálcica. Tornou-se evidente que a vesícula biliar só poderia ser visualizada se fosse contratastada, a exemplo do tubo digestivo (Goodman, I99I, pp. 2-I I).

Em I92 I, Evarts Ambrose Graham, professor de cirurgia na Washington University in St. Louis, nos Estados Unidos, interessou-se pelo problema e convidou um estudante do segundo ano, de nome Warren Henry Cole, para desenvolver um projeto nesse sentido. Os seguintes dados de descobertas anteriores serviram como ponto de partida para a investigação:

I. Os halogênios (cálcio, bromo e iodo) são opacos aos raios-X e seus compostos podem ser administrados por via venosa em seres vivos.

2. Radiografias contrastadas das vias urinárias haviam sido obtidas com a injeção intravenosa de iodeto de sódio.

3. O composto tetraclorofenolftaleína é excretado na bile, conforme haviam demonstrado Abel e Lowntree, em I909 (Abel e Rowntree, I909, pp. 23I-264).

4. Rous e McMaster haviam descoberto em I92 I a capacidade de concentração da bile (Rous e McMaster, I92 I, pp. 47-73).

Com estes elementos, Graham e Cole deram início às suas experiências e uma grande variedade de compostos halogenados foram testados em cães e coelhos. Com uma persistência incomum, Cole injetou por via intravenosa cerca de duzentos animais com diferentes compostos de tetrabromofenolftaleína e tetraiodofenolftaleína, sem obter o menor resultado. Em nenhum caso apareceu na radiografia a imagem da vesícula. Até que, em I923, Cole obteve em um cão, bem contrastada, a sombra densa da vesícula.

Ao contemplar a radiografia, Graham e Cole, entusiasmados, decidiram prosseguir com os experimentos. Nos dias seguintes, contudo, usando a mesma substância e a mesma técnica, nenhuma outra imagem semelhante foi obtida.

Cole decidiu rever a radiografia com a vesícula contrastada, temendo um erro de interpretação da imagem; poderia tratar-se, talvez, de um osso ou corpo estranho ingerido pelo cão. Enquanto examinava a radiografia entrou na sala o radiologista do hospital, dr. Walter Mills, que, de relance, olhando para o negatoscópio, perguntou a Cole: "Meu jovem colega, onde você conseguiu esta radiografia?”. Cole explicou-lhe o problema e sua dú- 

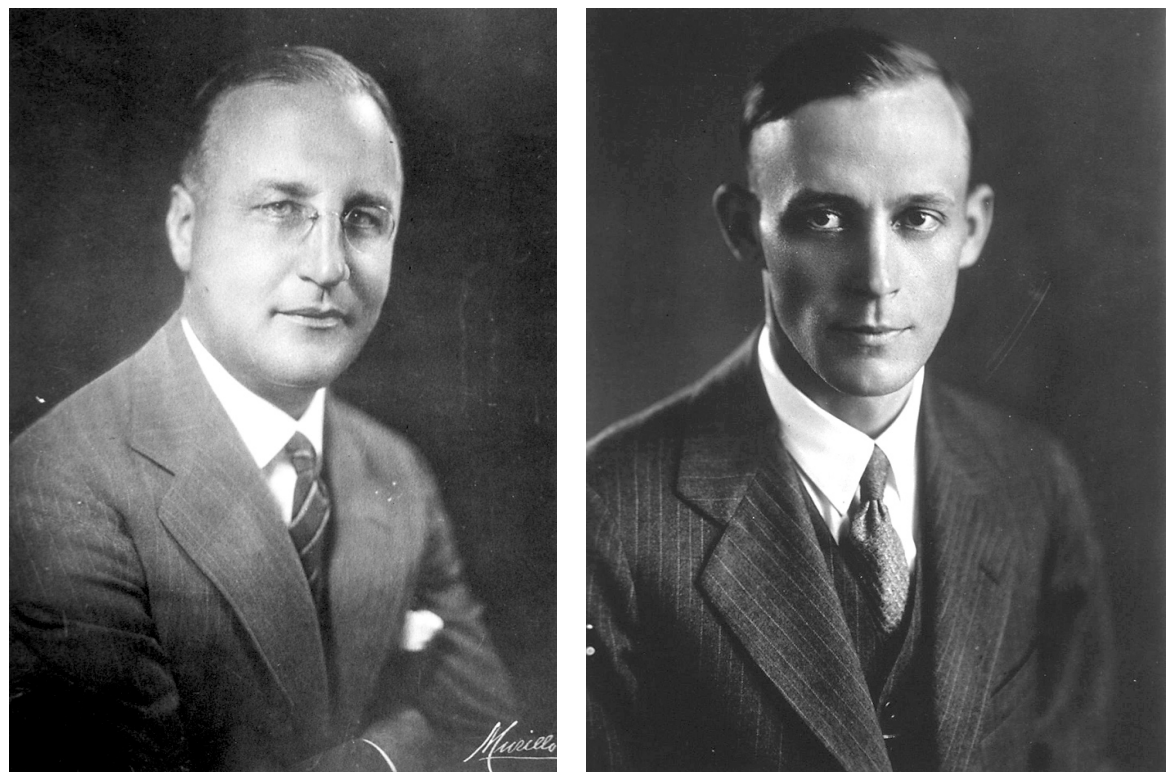

Evarts Ambrose Graham e Warren Henry Cole.

vida quanto à natureza da imagem. "Não seja tolo, rapaz, é a vesícula biliar e a imagem está tão nítida que a aplicação do método a seres humanos é somente uma questão de experimentação.”

Intrigado, Cole procurou o auxiliar de laboratório Bill, que cuidava dos cães, e indagou dele o que acontecera de diferente com aquele animal no dia em que o mesmo fora radiografado. De início, Bill disse não se lembrar de nada especial em relação àquele cão. Cole explicou-lhe que somente naquele animal havia conseguido um resultado satisfatório em suas pesquisas. "Bem, dr. Cole", retrucou Bill reticente, temendo uma admoestação: "houve uma diferença, sim, naquele dia eu me esqueci de dar alimento àquele cão pela manhã”. Cole, com os seus conhecimentos de fisiologia, encontrou de pronto a explicação para o fracasso das suas experiências. Eureca! Exultante, Cole avançou para abraçar Bill, que retrocedeu assustado. Ao ver o semblante alegre de Cole, no entanto, tranquilizou-se e recebeu um caloroso aperto de mão de seu chefe (Cole, I961, pp. 354-375).

Um simples acaso decorrente do descuido de um modesto tratador de cães veio esclarecer o enigma. A partir daí os cães passaram a ser injetados antes de serem alimentados e a vesícula se opacificou na maioria deles. 
Em I924 o método foi empregado pela primeira vez no ser humano; a substância injetada foi, inicialmente, a tetrabromofenolftaleína cálcica, logo substituída pela tetraiodofenolftaleína sódica, que produzia menos efeitos colaterais.

A verificação de que o contraste eliminado na bile é reabsorvido no intestino e reexcretado, mantendo a imagem da vesícula por algum tempo, levou à substituição da via venosa pela via oral para administração do contraste (Graham e Cole, I925, pp. I4-I6).

A partir de I925, até o advento da ultrassonografia na década de I970, a colecistografia oral foi o método utilizado rotineiramente para o diagnóstico das colecistopatias.

\section{Referências Bibliográficas}

Abel, J. J. \& Rowntree, L. G. “On the Pharmacological Action of Some Phtaleins and their Derivatives, with Special Reference to their Behavior as Purgatives”. Journal of Pharmacological and Experimenral Therapeutics, I, pp. 23 I-264, I909.

Cole, W. H. "Historical Features of Cholecystography". Radiology, 76, pp. 354-375, I96I.

Goodman, P. C. "Historia”. In Margulis, A. R. \& Burhenne, H. J. (orgs.). Radiologia del Aparato Digestivo, $4^{\underline{a}}$ ed. Buenos Aires, Ed. Medica Panamearicana, I99I.

Graham, E. A. \& Cole, W. H. "Cholecystography: An Experimental and Clinical Study". The Journal of the American Medical Association, 84 (I), pp. I4-I6, I925. Rous, P. \& McMaster, P. D. “The Concentrating Activity of the Gallbladder”. The Journal of Experimental Medicine, 34, pp. 47-73, I92 I. 